\title{
Synthesis, Characterization, and Testing of Pt-NPG Catalysts Developed by De-alloying of Electrodeposited $\mathrm{Cu}_{\mathrm{x}} \mathrm{Au}_{(1-\mathrm{x})}$ Thin Films
}

\author{
Jiaxin Xia, Innocent Achari, Stephen Ambrozik and Nikolay Dimitrov ${ }^{1}$ \\ Department of Chemistry, SUNY at Binghamton, PO Box 6000, Binghamton, NY 13902, USA
}

\begin{abstract}
:
Electrodeposited $\mathrm{Cu}_{\mathrm{x}} \mathrm{Au}_{(1-\mathrm{x})}$ thin films with different compositions have been found to undergo selective dissolution (de-alloying) in three specific potential ranges unlike their bulk counterparts known to de-alloy at composition dependent critical potentials. The general potential trend associated with co-existence of different thermodynamically stable alloy phases suggests increasing de-alloying rate in positive direction with the decreasing $\mathrm{Cu}$ content in the alloy. Following de-alloying, the resulting nanoporous Au (NPG) thin films exhibit significant surface area (SA) development, manifested by about three-fold increase in comparison with de-alloyed $\operatorname{Ag}_{x} A u_{(1-x)}$ precursor counterparts. SEM characterization have seconded the SA results by revealing a finer structure of the NPG films which feature pores and ligaments of less than $10 \mathrm{~nm}$. Formic acid oxidation tests suggest that the platinization of accordingly synthesized NPG thin films leads to the synthesis of catalysts exhibiting initial mass activities of 3-5 A.mg-1 (combined Pt-Au catalyst) and withstanding more than 2500 potential cycles.
\end{abstract}

Keywords: $\mathrm{Pt}$, nanoporous $\mathrm{Au}$, thin film, $\mathrm{Cu}-\mathrm{Au}$ alloys, de-alloying, platinization, catalysis, formic acid oxidation

1 Corresponding author Email: dimitrov@binghamton.edu ; Phone: 1 (607) 777-4271 ; Fax: 1 (607) 777-4478 


\section{Introduction}

In the aggressive search for energy sources alternative to fossil fuels, the use of fuel cells as one of key candidates is limited by the high cost of its catalyst, which mainly consists of Pt. In order to lower catalysts' cost, people have used various ways to minimize the use of Pt. One method is to coat $\mathrm{Pt}$ on a less expensive substrate, and also make the catalyst more rough and/or porous which results in the maximized surface area of the catalyst being exposed to the hydrogen or oxygen Nanoparticles (NPs) that have naturally large surface area-to-volume ratio and enhanced chemical reactivity are currently the preferred option for active carriers of catalytic reactions operating in today's fuel cells. Alternatively, nanoporous metals, with the best example being nanoporous Au (NPG), can also be used as a good candidate for catalyst skeletons [1]. The interconnected nano-sized pore and ligament structure results in the significantly larger surface area that NPG feature compared to that of a planar Au [2-4]. Once developed on a commonly C-based support, NPG films can be further functionalized with Pt or Pt-alloy coatings in order to form Pt-NPG, that can be further applied as the catalyst in the a variety of fuel cell related reactions [5].

An all-electrochemical approach has been introduced in our previous work for the development of catalysts for fuel-cell applications [5]. In this approach, $\operatorname{Au}_{x} \operatorname{Ag}_{(1-x)}$ thin films (TF) were first deposited on Au or glassy carbon (GC) substrates, and then the less noble metal, Ag, was subjected to selective electrochemical dissolution (de-alloying). As a result, the residual metal, $\mathrm{Au}$, structures itself in an interpenetrating solid-void framework with a single-digit nanometer length scale. Functionalized further with Pt, NPG thin film catalysts 
on Au and GC substrates have been tested for their catalytic activity and durability toward the formic acid (FA) oxidation reaction. The results demonstrate a remarkable initial activity in current density and mass activity. Developed thin films on Au substrates also can withstand over 2600 cycles in standard FA oxidation testing with peak current densities in the range 40-50 $\mathrm{mA} \mathrm{cm}^{-2}$ and mass activities of 1-3 $\mathrm{A} \mathrm{mg}^{-1}$ (of combined Pt-Au catalyst).[5] Some other techniques have also been introduced in order to address issues revealed during the course of NPG fabrication on GC substrates. More specifically, electrochemical oxidation[6] and thermochemical oxidation pre-treatments [7] of GC substrates were used to improve the adhesion between NPG and GC substrates, and seeding approaches [8,9] were implemented to enhance the nucleation density and facilitate the lateral cluster coalescence in the course of alloy electrodeposition. Overall, a continuous thin film of NPG with good catalyst activities has been successfully fabricated on both Au and GC substrates [5-8].

After completing the research on the Ag-Au system, we have steered our effort to the exploration of alternative avenues for NPG synthesis. Our interest has focused recently on studies of the impact of structure and composition on the de-alloying of bulk $\mathrm{Cu}_{\mathrm{x}} \mathrm{Au}_{(1-\mathrm{x})}$ and $\mathrm{Cu}-\mathrm{Au}$ nanorods alloys [10]. This choice of $\mathrm{Cu}$ as alloying element is associated with its lower cost and higher catalytic activity in comparison with Ag. In recent work we reported on a study comparing the de-alloying of different compositions of bulk $\mathrm{Cu}_{\mathrm{x}} \mathrm{Au}_{(1-\mathrm{x})}$ alloys $[11,12]$ and in $\operatorname{Ag}_{x} A_{u}(1-x)$ counterpart alloys [13]. As a result, the critical potential ( $\left.E_{c}\right)$ was found to shift positively with the increase of the $\mathrm{Au}$ content in $\mathrm{Cu}_{\mathrm{x}} \mathrm{Au}_{(1-\mathrm{x})}$ bulk alloys similar to the trend observed for $\mathrm{Ag}_{\mathrm{x}} \mathrm{Au}_{(1-\mathrm{x})}$, and $\mathrm{Cu}_{\mathrm{x}} \mathrm{Pt}_{(1-\mathrm{x})}$ [14] alloys. Beside this, and unlike its $\mathrm{Ag}$ and $\mathrm{Pt}$ 
containing counterparts the $\mathrm{Cu}_{\mathrm{x}} \mathrm{Au}_{(1-\mathrm{x})}$ bulk alloys were shown to exhibit de-alloying behavior with three distinct stages in the respective anodic polarization curves [10, 11, 13]. Ranges of limited and complete de-alloying were ascertained with $\mathrm{Pb}$ underpotential deposition (UPD) and scanning electron microscopy (SEM) characterization and were associated with de-alloying at lower (in stage II [10]) and higher potentials (in stage III [10]), respectively. Also, two kinds of $\mathrm{Cu}_{3} \mathrm{Au}$ nanorods (intermetallics and random alloys) were studied with anodic polarization curves and Electrochemical Quartz Crystal Microbalance (EQCM) tests $[10,15]$, and the results demonstrated that the de-alloying process for both samples was initiated at about $0.40-0.43 \mathrm{~V}$ positive to the $\mathrm{Cu} / \mathrm{Cu}^{2+}$ reversible potential with a tiny difference between them. Thus, when comparing the de-alloying behavior of bulk alloys and the nanorods with identical composition, the $\mathrm{E}_{\mathrm{c}}$ of both types of nanoparticles was found to shift negatively (by c.a. of $0.20 \mathrm{~V}$ ). As stated in our previous report [10], this comparison confirmed the size and structural trends seen earlier in the Ag-Au system [16] de-alloying.

Given the confirmed suitability of nanoporous metals for applications based on their optical and catalytic properties along with the remarkable tunability of structure and composition of NPG, $[15,17-20]$ the de-alloying study in the system $\mathrm{Cu}-\mathrm{Au}$ is worth pursuing. Moreover, the results of FA oxidation testing not only showed good activity and durability performance of Pt-coated $\mathrm{Cu}_{3} \mathrm{Au}$ nanorods and but also revealed unusually enhanced activity of Au enriched structures resulting from their de-alloying. This suggests the possibility of achieving similar performance by Pt-NPG processed by comprehensively controlled de-alloying of electrodeposited ultra thin films of $\mathrm{Cu}_{\mathrm{x}} \mathrm{Au}_{(1-\mathrm{x})}$ alloy. Our literature 
review suggests that while some work has been done on studying the behavior of $\mathrm{Cu}-\mathrm{Au}$ thin films synthesized by a free-corrosion approach or DC magnetron sputtering [21-23], no studies have been dedicated to introducing and developing all-electrochemical approaches for generating the NPG catalysts using $\mathrm{Cu}$-Au thin film alloys. Setting the latter as the main objective of this work, the research will primarily focus on (i) a systematic study of the de-alloying behavior of different composition $\mathrm{Cu}-\mathrm{Au}$ thin films electrodeposited from controlled composition solutions, (ii) the surface area development for NPG structures processed by the de-alloying of the previously deposited $\mathrm{Cu}_{\mathrm{x}} \mathrm{Au}_{(1-\mathrm{x})}$ films with different compositions, and (iii) the catalytic activity and durability of accordingly synthesized NPG, coated later with an ultra-thin film of Pt in FA oxidation tests.

The composition of $\mathrm{Cu}-\mathrm{Au}$ thin films fabricated with different ratio $\mathrm{Cu}$ and $\mathrm{Au}$ deposition solutions is determined by energy dispersive X-ray spectroscopy (EDX), the study of the de-alloying behavior of different composition $\mathrm{Cu}-\mathrm{Au}$ thin film alloys is carried out and the structural characteristics of the resulting NPG structures have been discussed. Along with the de-alloying behavior, $\mathrm{Pb}$ UPD method was used to examine the change of surface area [24], and SEM was employed to image the morphology after de-alloying. Finally, basic tests on the catalytic properties of Pt-coated NPG during FA oxidation are reported and discussed with a focus on shape and structural differences $[5,16]$. Along with the catalyst development, all results of $\mathrm{Cu}-\mathrm{Au}$ thin film de-alloying are compared with the behavior of $\mathrm{Cu}-\mathrm{Au}$ bulk alloys and $\mathrm{Cu}_{3} \mathrm{Au}$ nanorods as well as with the selective dissolution of $\mathrm{Ag}$ in the $\mathrm{Ag}-\mathrm{Au}$ counterpart alloys. 


\section{Experimental Section}

2.1. Electrode Preparation. Polycrystalline cylindrical Au (99.99\%) working electrodes (diameter $6 \mathrm{~mm}$ ) were mechanically polished down to $1 \mu \mathrm{m}$ with alumina powder on a Buehler polishing pad. Then the Au electrodes were rinsed with Barnstead Nanopure ${ }^{\circledR}$ water $(\mathrm{R} \geq 18.2 \mathrm{M} \Omega \mathrm{cm}$ ) followed by sonication for five minutes and rinsing with Barnstead Nanopure $^{\circledR}$ water again. After sonication, the Au electrodes were dried under ultra high purity $\mathrm{N}_{2}$ (less than $1 \mathrm{ppb}$ of $\mathrm{O}_{2}, \mathrm{CO}, \mathrm{CO}_{2}$ and moisture). Before use, the $\mathrm{Au}$ samples were submerged in concentrated $\mathrm{HNO}_{3}$ at $50^{\circ} \mathrm{C}$ to eliminate any potential traces of metal ions or remnants of the polishing paste followed again by rinsing with Barnstead Nanopure ${ }^{\circledR}$ water.

2.2. Thin Film Alloy Deposition. A Princeton Applied Research (PAR) Model 273 Potentiostat/Galvanostat with Corrware Software was been used to electrochemically deposit $\mathrm{Cu}-\mathrm{Au}$ thin films with solutions containing $1 \mathrm{mM} \mathrm{Au}(\mathrm{I}) \mathrm{NaS}_{2} \mathrm{O}_{3}$ (Alfa AESAR, Ward Hill, MA, USA; $99.9 \%$ ) complex to provide $\mathrm{Au}^{+}$cations and $1 \mathrm{mM} \mathrm{CuSO}_{4}$ (Aldrich Chemicals, $99.995 \%$ ) provide $\mathrm{Cu}^{2+}$ cations in $0.1 \mathrm{M} \mathrm{Na} \mathrm{S}_{2} \mathrm{O}_{3}$ (Alfa AESAR, Ward Hill, MA, USA; $\geq 99 \%$ ) solution. Three different solutions have been used to form $\mathrm{Cu}-\mathrm{Au}$ thin film with molar ratios of 1:1, 3:1, and $5: 1$ by changing $\mathrm{CuSO}_{4}$ concentration to $1 \mathrm{mM}, 3 \mathrm{mM}$ or $5 \mathrm{mM}$. All solutions were freshly used to prevent spontaneous metal reduction. The alloys were electrodeposited on $\mathrm{Au}$ samples in a three-electrode cell at a constant potential of $-0.400 \mathrm{~V}$ vs. $\mathrm{Cu} / \mathrm{Cu}^{2+}$ pseudo reference electrode (PRE). A Pt wire was used as the counter electrode (CE). The cell was purged with ultra high purity $\mathrm{N}_{2}$ for 20 minutes before use. The thickness of the films was controlled by the duration of the applied potential. An identical amount of deposited alloy 
with a given composition for all samples was ensured through determination of the deposition efficiency calculated as the ratio of charge of de-alloyed $\mathrm{Cu}$ (see next step) to the total deposition charge (fixed at $200 \mathrm{mC} . \mathrm{cm}^{-2}$ in all experiments). Following alloy deposition, the samples were rinsed thoroughly with Barnstead Nanopure ${ }^{\circledR}$ water and dried gently under ultra high purity $\mathrm{N}_{2}$. An additional deposit of each ratio was performed on $\mathrm{GC}$ at the same potential with the same charge, and then these samples were used for EDX analysis (see step 2.5) to determine the exact ratio of $\mathrm{Cu}-\mathrm{Au}$ in the deposit. After deposition, $\mathrm{Pb}$ UPD was performed immediately to determine the SA of the deposited thin film alloys.

2.3. The De-alloying Process. Selective removal of $\mathrm{Cu}$ from the $\mathrm{Cu}-\mathrm{Au}$ polycrystalline alloy (de-alloying) was carried out by linear sweep voltammetry to obtain NPG. The de-alloying experiments were performed in a three-electrode cell filled with $1 \mathrm{mM} \mathrm{CuSO} 4$ and $0.1 \mathrm{M} \mathrm{HClO}_{4}$ (GFS Chemical, 70\% redistilled). A Pt wire was used as CE. A PAR Model 273 Potentiostat/Glavanostat with Corrware Software was used to perform anodic scans from $0.10 \mathrm{~V}$ to $1.25 \mathrm{~V}$ versus $\mathrm{Cu} / \mathrm{Cu}^{2+} \mathrm{PRE}$ at a sweep rate of $1 \mathrm{mV} \cdot \mathrm{s}^{-1}$.

2.4. Surface Area (SA) Measurements: Pb UPD and H UPD. Pb UPD was performed before the alloy deposition and after de-alloying to determine the SA of polished flat Au precursor and the synthesized NPG. The measurements were performed by cyclic voltammetry in a three-electrode cell with $\mathrm{Pt}$ wire that served as $\mathrm{CE}$. The solution used for $\mathrm{Pb}$ UPD contained 0.1 $\mathrm{M} \mathrm{NaClO}_{4}$ (Sigma, 99.95\%), $3 \mathrm{mM} \mathrm{Pb}\left(\mathrm{ClO}_{4}\right)_{2}$ (Aldrich, 99.995\%), and $0.01 \mathrm{M} \mathrm{HClO}_{4}$. The solution was purged with ultra high purity $\mathrm{N}_{2}$ for 20 minutes prior to $\mathrm{Pb}$ UPD experiments, followed by gently passing $\mathrm{N}_{2}$ over the surface of the solution during the 
anodic scans. A BASi Epsilon Electrochemical Workstation was used for cycling the potential at $20 \mathrm{mVs}^{-1}$ from 0.9000 to $-0.010 \mathrm{~V}$ versus $\mathrm{Pb} / \mathrm{Pb}^{2+} \mathrm{PRE}(-0.200 \mathrm{~V}$ vs. standard hydrogen electrode, SHE). Functionalized electrodes were assessed for SA by H UPD performed on the surface from +0.400 to $-0.680 \mathrm{~V}$ at $50 \mathrm{mV} \mathrm{s}^{-1}$ vs. Mercurous-mercury sulfate reference electrode (MSE) in a $0.5 \mathrm{M} \mathrm{H}_{2} \mathrm{SO}_{4}$ (GFS Chemical, redistilled 95-98\%) solution. The solution was purged with nitrogen for $2 \mathrm{~h}$ prior to $\mathrm{H}$ UPD and had $\mathrm{N}_{2}$ gas passed over the surface of the solution during the analysis. The charge was calculated by running chronoamperometry at $-0.690 \mathrm{~V}$ for the negative scan and at $-0.400 \mathrm{~V}$ for the positive scan, and then averaging the integration of both curves.[5] In all electrochemical experiments the $\mathrm{Au}$ electrodes were in contact with the electrolyte in hanging meniscus configuration as described elsewhere[25].

2.5. SEM and EDX Spectroscopy: SEM, (Zeiss Supra 55 VP) coupled with an in lens detector at an accelerating voltage of $10 \mathrm{kV}$ and a working distance of $2 \mathrm{~mm}$ was performed for the morphological characterization of de-alloyed thin films. The alloy composition was also independently confirmed by EDX on alloy films deposited on GC substrates using an FEG-SEM Zeiss Supra 55 VP coupled with a through-the-lens detector at an accelerating voltage of $10-15 \mathrm{kV}$, used for imaging at magnifications up to $200,000 \mathrm{X}$.

2.6. Pt Functionalization. Five replacements of $\mathrm{Pb}$ UPD layer by $\left[\mathrm{PtCl}_{4}\right]^{2-}$ complex $[5$, 26] using surface-limited redox replacement with an OMNI 90 (Cypress Systems) potentiostat coupled to a Cypress Systems coupling electronics module and National Instruments analog-to-digital converting board were performed on the de-alloyed Au samples 
in a solution containing $0.1 \mathrm{M} \mathrm{NaClO}_{4} 10 \mathrm{mM} \mathrm{HClO}_{4}, 1 \mathrm{mM} \mathrm{Pb}\left(\mathrm{ClO}_{4}\right)_{2}$, and $0.5 \mathrm{mM}$ $\mathrm{K}_{2} \mathrm{PtCl}_{4}$ (GFS Chemical, 98\%) and recorded using Dasylab 9.00 software, following a protocol recently developed by our group $[5,26]$. A 1 s pulse at $-0.830 \mathrm{~V}$ vs. mercury-mercurous sulfate, MSE was applied to allow percolation of the $\mathrm{Pb}$ throughout the nanoporous structure forming a monolayer on the NPG surface. Then applied potential was released and the potential was monitored until it reached $+0.050 \mathrm{~V}$ and in the process a redox replacement of $\mathrm{Pb}$ monolayer by $\mathrm{Pt}$ occurs. At this high limit, the pulse was reapplied and the cycle resumed for each replacement thus producing Pt-NPG. Pt wire was used as a counter electrode.

2.7. Formic Acid Oxidation. Prior to formic acid oxidation reactions, the samples were electrochemically annealed by rapidly scanning $\left(300 \mathrm{mV} \mathrm{s}^{-1}\right)$ between -0.740 and $+0.450 \mathrm{~V}$ in the H UPD solution for 50 cycles to activate the surface. The testing followed a procedure developed and described in our earlier work [27]. More specifically, FA oxidation was performed on the Pt-NPG surface in $2 \mathrm{M} \mathrm{HCOOH} \mathrm{(JT} \mathrm{Baker,} \mathrm{88 \% ),} \mathrm{and} 0.1 \mathrm{M} \mathrm{HClO}_{4}$ from -0.510 to $+0.700 \mathrm{~V}$ vs. MSE repetitively until the current density decayed to about zero. After a certain number of cycles, the working electrode was removed from the formic acid testing cell and checked with H UPD to ensure that the surface was still intact and to measure the electrochemically active surface area (ECASA) [26, 28].

\section{Results and Discussion}

\subsection{Nanoporous $\mathrm{Au}$ thin film fabrication process through $C \mathrm{u}_{x} A u_{(1-x)}$ de-alloying}


As stated earlier, $\mathrm{Cu}_{\mathrm{x}} \mathrm{Au}_{(1-\mathrm{x})}$ alloys used in this work as NPG precursors were prepared only by electrodeposition. EDX results presented concisely in Table 1 reveal that the $\mathrm{Cu}^{2+}: \mathrm{Au}^{+}$ratios of $5: 1,3: 1$, and $1: 1$ used in the deposition solution produced $\mathrm{Cu}: \mathrm{Au}$ ratios (in at $\%$ ) of 82:18, 73:26, and 52:48, respectively. As we mentioned elsewhere, Au (I) thiosulfate has a larger stability constant, $\beta_{\mathrm{Au}}=1.3 \times 10^{26}$, than $\mathrm{Cu}$ (I) thiosulfate, $\beta_{\mathrm{Cu}}=2.5 \times 10^{10}$, so that more free $\mathrm{Cu}^{2+}$ ions than $\mathrm{Au}^{+}$ions would be available for reduction on the electrode upon application of negative enough potential. This explains the slightly higher content of $\mathrm{Cu}$ atoms in the deposited thin films in comparison with the ionic content in the precursor solution $[5,29,30]$.

After deposition, the $\mathrm{Cu}_{\mathrm{x}} \mathrm{Au}_{(1-\mathrm{x})}$ thin films were electrochemically de-alloyed in order to fabricate the NPG. Figure 1 demonstrates the de-alloying behavior of different composition $\mathrm{Cu}_{\mathrm{x}} \mathrm{Au}_{(1-\mathrm{x})}$ thin films. Similarly with $\mathrm{Cu}-\mathrm{Au}$ bulk alloys [10], a multistage de-alloying is observed for all $\mathrm{Cu}-\mathrm{Au}$ thin films. In Figure 1, the de-alloying curves of all three compositions exhibit a significant peak in the potential range $0.18-0.28 \mathrm{~V}$ vs. the $\mathrm{Cu} / \mathrm{Cu}^{2+}$ PRE, which corresponds to stage I of de-alloying curve of the $\mathrm{Cu}-\mathrm{Au}$ bulk alloys. This potential range was associated with the dissolution of $\mathrm{Cu}$ atoms from non-bonded or low coordination surface sites. The onset of a second peak is seen positive of $0.62 \mathrm{~V}$ and culminates in the range $0.83-0.86 \mathrm{~V}$, which matches the stage II in the de-alloying of $\mathrm{Cu}-\mathrm{Au}$ bulk alloys [10]. Also, a third peak emerges at around $0.9 \mathrm{~V}$ and features maximum intensity at about $1.0 \mathrm{~V}$, in the potential range of stage III [10] where a fast rate selective dissolution of $\mathrm{Cu}-\mathrm{Au}$ bulk alloy takes place. In our previous paper [10], we presented the de-alloying curves 
of $\mathrm{Cu}_{0.80} \mathrm{Au}_{0.20}$ and $\mathrm{Cu}_{0.70} \mathrm{Au}_{0.30}$ bulk alloys along with literature data for $\mathrm{Cu}_{0.75} \mathrm{Au}_{0.25}$ [11]. The de-alloying behavior of two types $\mathrm{Cu}_{3} \mathrm{Au}$ nanorods was also discussed. It was demonstrated that similarly to the Ag-Au system [31], the bulk and nanoparticulate $\mathrm{Cu}-\mathrm{Au}$ samples exhibited $\mathrm{E}_{\mathrm{c}}$ that was strongly dependent upon the alloy composition and sample size. More specifically, critical potentials of $0.54,0.72$ and about $0.40 \mathrm{~V}$ vs. $\mathrm{Cu} / \mathrm{Cu}^{2+}$ were measured for $\mathrm{Cu}_{0.80} \mathrm{Au}_{0.20}, \mathrm{Cu}_{0.70} \mathrm{Au}_{0.30}$ bulk alloys and $\mathrm{Cu}_{3} \mathrm{Au}$ nanorods, respectively [10]. In contrast to this, the analysis of the de-alloying curves in Figure 1 suggests no shift in the $E_{c}$ for electrodeposited $\mathrm{Cu}-\mathrm{Au}$ alloy thin films with substantial compositional variation. Instead, for the latter sample set the de-alloying takes place in identical potential ranges, albeit the amount of dissolved $\mathrm{Cu}$ is different in each of these potential ranges for samples with different compositions. One possible reason for this oxidation behavior could be the co-existence of different phases in thin films with various $\mathrm{Cu}$ :Au ratios. Support for this hypothesis comes from our previous paper [10], where XRD results ascertained the co-existence of various orientations in the bulk $\mathrm{Cu}$-Au alloys with different composition. It is noteworthy that the $\mathrm{Cu}-\mathrm{Au}$ thin films studied in this work were fabricated at ambient (room) temperature. Based on the $\mathrm{Cu}-\mathrm{Au}$ phase diagram $[32,33]$, at room temperature, all intended compositions would eventually form mixtures of three possible phases that could co-exist thermodynamically, namely $\mathrm{Cu}_{3} \mathrm{Au}$ (including $\mathrm{Cu}_{3} \mathrm{AuI}$, tetragonal structure and $\mathrm{Cu}_{3} \mathrm{AuII}$, rhombic structure), $\mathrm{CuAu}$ (including $\mathrm{CuAuI}$ and $\mathrm{CuAuII}$ ), and $\mathrm{CuAu}_{3}$. Apparently, owing to the drastically different $\mathrm{Au}$ content these phases undoubtedly de-alloy at different $\mathrm{E}_{\mathrm{c}}$. Therefore, it is reasonable to expect each of the three single phase $\mathrm{Cu}$ - $\mathrm{Au}$ alloys to de-alloy in 
different potential ranges. Thus, each of the alloy thin films would have different content of aforementioned single phase $\mathrm{Cu}-\mathrm{Au}$ alloys based on deposition conditions. Consequently, alloys enriched in $\mathrm{Cu}$ would feature more $\mathrm{Cu}_{3} \mathrm{Au}$ phase and alloys with more $\mathrm{Au}$ would contain more $\mathrm{CuAu}_{3}$. These configurations differ dramatically to the bulk samples because of the thermodynamic stabilization of a variety of single phase $\mathrm{Cu}-\mathrm{Au}$ alloys obtained by melting and quenching at temperatures higher than those of phase separation.

Further analysis of the curves in Figure 1 can be done to understand quantitatively the $\mathrm{Cu}-\mathrm{Au}$ thin film unique de-alloying behavior. For all three compositions in Figure 1, the beginning of stage II (identified in [10] as critical potential, $\mathrm{E}_{\mathrm{c}}$ ) is at around $0.65 \mathrm{~V}$, with a virtually negligible difference from alloy to alloy. These results clearly demonstrate that the $\mathrm{Cu}-\mathrm{Au}$ thin film composition practically does not impact the $\mathrm{E}_{\mathrm{c}}$ as a whole. It is also noteworthy that the de-alloying critical potential of $\mathrm{Cu}-\mathrm{Au}$ thin films is still far positive than that of $\mathrm{Cu}-\mathrm{Au}$ nanorods, and similarly the $\mathrm{Ag}-\mathrm{Au}$ system [16, 34], features a positive excursion (of about $0.2 \mathrm{~V}$ ) that exceeds substantially that naturally associated with Gibbs-Thomson (curvature) effects and predicted theoretically [35] to be of order of $0.05 \mathrm{~V}$. More detailed information can be obtained from the curves in Figure 1 on the relative amount of $\mathrm{Cu}$ dissolving in different potential ranges as a function of the $\mathrm{Cu}-\mathrm{Au}$ thin film composition. As seen in the figure, the 5:1 ratio $\mathrm{Cu}-\mathrm{Au}$ thin film features a highest peak in the potential range $0.18-0.28 \mathrm{~V}$ (stage I) and lowest peaks in the range encompassing 0.8 to $1.1 \mathrm{~V}$ (stage II and III). On the contrary, the 1:1 ratio $\mathrm{Cu}-\mathrm{Au}$ thin film has its lowest peak in stage I and highest in stages II and III. In an intermediate position is the curve of the 3:1 ratio $\mathrm{Cu}-\mathrm{Au}$ 
thin film that exhibits peak heights/areas in between the other two compositions. A detailed examination of all peaks for each curve enabled the calculation of the total stripped charge as presented in Table 1 . The charges listed in Table 1 suggest that with more $\mathrm{Cu}$ in the alloy, predominantly the non-bonded or low coordination surface sites will be active in the dissolution process, resulting in most of the copper being dissolved at a lower potentials (stage I) and vice-versa, less amount of $\mathrm{Cu}$ leads to de-alloying at a higher potentials. This hypothesis developed in agreement with the earlier discussed trends in the $\mathrm{Cu}-\mathrm{Au}$ phase diagram by the measured de-alloying charges. For instance, when more than $80 \%$ of the film is $\mathrm{Cu}\left(\mathrm{Cu}: \mathrm{Au} \approx 5: 1\right.$ ratio), the dominating phases are $\mathrm{Cu}, \mathrm{Cu}_{3} \mathrm{AuI}$ and $\mathrm{Cu}_{3} \mathrm{AuII}[32,33$. Therefore, a large amount of weakly bonded $\mathrm{Cu}$ was de-alloyed at lower potentials, which exhibit high peak in stage I, and lower peak in stage II and III. When the $\mathrm{Cu}$ content in the film is about $50 \%(\mathrm{Cu}: \mathrm{Au} \approx 1: 1)$, the co-existing phases are mostly $\mathrm{Cu}_{3} \mathrm{AuI}, \mathrm{Cu}_{3} \mathrm{AuII}, \mathrm{CuAuI}$ and CuAuII [33]. A small amount of $\mathrm{CuAu}_{3}$ could be present in the alloy as well. Consequently, the de-alloying process is most pronounced in stages II and III which correspond to the de-alloying of phase $\mathrm{Cu}_{3} \mathrm{Au}, \mathrm{CuAu}$, and $\mathrm{AuCu}_{3}$. This leads to a lower peak area in stage I and increased peak area in stage II and III. Overall, as mentioned earlier, $\mathrm{E}_{\mathrm{c}}$ virtually remains constant while the peak ratio between stage I and the other two stages increases with the increase of the $\mathrm{Cu}$ content in the alloy (see column $\mathrm{D}$ in Table 1).

Table 1 also shows the overall charge accumulated during the alloy deposition process for all three compositions. Surprisingly, the comparison between deposition and dissolution charge suggests systematically higher values of the latter process. Thus, the sample with 5:1 
$\mathrm{Cu}: \mathrm{Au}$ ratio, features a total deposition charge of $306.6 \mathrm{mC} . \mathrm{cm}^{-2}$, which accounts for the total amount of $\mathrm{Au}$ and $\mathrm{Cu}$ atoms that have been deposited on the substrate. During the de-alloying process, only the $\mathrm{Cu}$ atoms oxidize and dissolve into the solution, while the $\mathrm{Au}$ stays and organizes itself in a porous structure. Therefore, the charge stripped during de-alloying process should be less than that deposited. However, the de-alloying process for the 5:1 ratio sample yielded a stripping charge of $519.2 \mathrm{mC} . \mathrm{cm}^{-2}$ that exceeds significantly the deposition one. The reason for this high stripping charge is most likely related to the $\mathrm{Cu}$ state of oxidation in the deposition solution. As shown in the experimental section, $0.1 \mathrm{M} \mathrm{Na} \mathrm{S}_{2} \mathrm{O}_{3}$ solution has been used as deposition solution and $\mathrm{CuSO}_{4}$ was added to it to provide $\mathrm{Cu}^{2+}$ cations. It has been shown that under these circumstances the $\mathrm{Cu}^{2+}$ cations will immediately react with $\mathrm{S}_{2} \mathrm{O}_{3}{ }^{2-}$ and reduce themselves to $\mathrm{Cu}^{+}$cations coupled with the oxidation of thiosulfate to tetrathionate $\left(2 \mathrm{Cu}^{2+}+2 \mathrm{~S}_{2} \mathrm{O}_{3}{ }^{2-} \rightarrow 2 \mathrm{Cu}^{+}+\mathrm{S}_{4} \mathrm{O}_{6}{ }^{2-}\right)$.[36] As a result of this reduction, the deposition process involves reduction of (mostly) $\mathrm{Cu}^{+}$(to $\mathrm{Cu}$ metal) instead of the originally introduced $\mathrm{Cu}^{2+}$ cations. Thus, the overall deposition charge would be substantially less than expected if $\mathrm{Cu}^{2+}$ cations were involved. At the same time, the $\mathrm{Cu}-\mathrm{Au}$ thin film de-alloying takes place in sulfate based electrolyte where the elemental $\mathrm{Cu}$ oxidizes normally to $\mathrm{Cu}^{2+}$ cations in perchlorate solution which doubles the charge needed specifically for $\mathrm{Cu}$ deposition. Under the coarse assumption that all of the deposited $\mathrm{Cu}$ is being reduced from a $\mathrm{Cu}^{+}$species and all of the $\mathrm{Cu}$ stripped during de-alloying is being oxidized to $\mathrm{Cu}^{2+}$ then the de-alloying charge can be converted in terms of deposition charge by simply dividing it by 2 . In doing this in particular for the 5:1 Cu:Au ratio sample then actual amount of charge that 
was collected during $\mathrm{Cu}$ de-alloying could then be calculated as $259.6 \mathrm{mC} . \mathrm{cm}^{-2}$. This constitutes $84.7 \%$ of the total deposition charge within the range of acceptable outcomes. The latter result was corroborated by independent EDX results that yielded $82.0 \% \mathrm{Cu}$ content in the same 5:1 Cu:Au sample.

\subsection{Surface area determination through high roughness factor calculations.}

$\mathrm{Pb}$ UPD cyclic voltammetry $(\mathrm{CV})$ curves for all three compositions of $\mathrm{Cu}-\mathrm{Au}$ thin films are presented in Figure 2. The red curves represent the surface area (SA) of the polycrystalline $\mathrm{Au}$ substrate before deposition, and the blue curves are associated with the SA of NPG fabricated by the de-alloying process [37]. The explicitly calculated SA of the NPG has also been included in Table 2 and the SA development is listed and compared with Ag-Au alloy thin films with similar composition [5]. The numbers in parentheses in Table 2 presented herein for the sake of comparison are the adjusted SA to a case in which if all total deposition charges were equal to $214 \mathrm{mC} \cdot \mathrm{cm}^{-2}$. Both Figure 2 and Table 2 show the significant increase surface area for all three thin film compositions. It is clearly seen that the 1:1 ratio sample features the highest $\mathrm{SA}$ that is 22.7 times higher than the flat polycrystalline Au sample before the deposition process. Due to the fact that the 1:1 ratio has more Au in the thin film, the de-alloying process results in a nanoporous structure with high density and small-size holes, which in turn results in high SA development. On the contrary, when the de-alloying takes place in 5:1 $\mathrm{Cu}: \mathrm{Au}$ ratio thin films, a large amount of $\mathrm{Cu}$ oxidatively dissolves, leaving non-uniformly distributed, large openings with a greater tendency of ligament coalescence that eventually results in about three times smaller SA. It is also clearly 
seen from Table 2 that the SA development in the present study is about twice as high as in NPG samples synthesized by de-alloying of Ag-Au thin film alloys with the same composition (see the results from ref. 3 presented in Table 2). Therefore, the NPG fabricated through $\mathrm{Cu}-\mathrm{Au}$ thin film de-alloying appears as better choice for a large SA substrate that becomes a catalyst after further coating with Pt or Pt based alloys.

In support of the SA analysis in the previous paragraph, SEM/EDX measurements were performed using a FEG-SEM Supra 55VP. Figure 3 shows low and high magnification images of NPG fabricated by de-alloying of two $\mathrm{Cu}-\mathrm{Au}$ thin films with different compositions. A set of SEM images of NPG fabricated by de-alloying of $\operatorname{Ag}_{0.75} \mathrm{Au}_{0.25}$ thin films on Au substrate has also been inserted for comparison. In both $20 \mathrm{~nm}$ scale-bar images, pores that implicate generally the site of de-alloyed $\mathrm{Cu}$ atoms can be seen clearly. The size of the holes in both samples is of order of $10 \mathrm{~nm}$. A comparison of both $\mathrm{Cu}-\mathrm{Au}$ samples with different compositions suggest that the $\mathrm{Cu}_{0.53} \mathrm{Au}_{0.47}$ alloy exhibits continuous and smaller holes on the surface, while, the $\mathrm{Cu}_{0.83} \mathrm{Au}_{0.17}$ thin films deposit from 5:1 ratio $\mathrm{Cu}$ - $\mathrm{Au}$ solutions feature a similar fine structure along with larger and non-uniformly spread, isolated holes. These results ascertain qualitatively the expectation of high SA development for these two thin films and suggest indirectly that the 1:1 ratio $\mathrm{Cu}-\mathrm{Au}$ thin film should exhibit higher roughness factor. When comparing with the NPG fabricated by $\operatorname{Ag}_{0.75} \mathrm{Au}_{0.25}$ thin films, the holes in the Ag-Au sample appear somewhat bigger with a size of about 10-20 nm. As discussed above, the smaller $\mathrm{Cu}$ atom's size in comparison with the Ag most likely contributes to the generation of NPG material with smaller holes. 


\subsection{Formic acid oxidation testing of Platinized Nanoporous Au thin films}

In this work, a NPG sample generated by the de-alloying of 5:1 and 1: 1 ratio $\mathrm{Cu}-\mathrm{Au}$ thin film alloys have been selected for FA oxidation tests. Before the catalyst testing, a Pt ultrathin film (2-3 ML thick) was coated on both NPG samples using SLRR of Pb UPD layer by $\left[\mathrm{PtCl}_{4}\right]^{2-}$ complex [26] following routines developed in our previous work [5]. Figure 4 shows the potential transients registered for a five-cycle SLRR deposition of Pt on the respective NPG sample. Following the platinization, SA measurements were performed by H UPD on the Pt-coated surface. Detailed characteristic peaks of H UPD formation and stripping on/from the platinized surface in the -0.670 to $0.400 \mathrm{~V}$ potential range are shown in Figure 5 . It is clearly seen in Figure 5 that the loss of surface area as determined by integration H UPD CV curves, decay slowly and steadily for both tested samples up to about 1500 cycles. The SA area trends with testing cycles were similar in our previous work [5] whereby the loss of catalytically active surface was associated predominantly with Pt dissolution [38]. More specifically, this was based on the behavior of flat Au electrodes which Pt coatings of identical thicknesses dissolve almost completely after 2500 cycles of testing in FA [38]. In the present work results of the FA test at different number of cycles are presented in Figure 6. The curves show that the $\mathrm{CO}$ oxidation peaks are initially at approximately $0.40 \mathrm{~V}$ for $1: 1$ $\mathrm{Cu}-\mathrm{Au}$ thin films and $0.35 \mathrm{~V}$ for $5: 1$ thin films. The catalysts activity was measured on negative potential scanning, whereby a current peak was recorded. It is noteworthy that the FA oxidation peak associated with the breakup of the passivity layer on the catalyst surface is found initially at very positive potentials, especially on the 1:1 Au:Cu electrode (Figure 6). In 
our previous work similar behavior was exhibited by de-alloyed $\mathrm{Cu}_{3} \mathrm{Au}$ nanorods that were coated with identical thickness Pt films [10]. In that case, the enhanced catalytic performance was manifested by virtual lack of hysteresis in the very beginning of the tests, followed alike with results of our present work by a steady negative shift of the peak with cycling in cathodic direction. Determined this way, the FA oxidation results showed high initial activity for the catalysts on both tested samples, with peak current densities ranging from 10 to 14 $\mathrm{mA} \cdot \mathrm{cm}^{-2}$, respectively. Compared with other Pt or Pt-based alloy nanoparticles shown previously to produce peak current densities of about $2.5 \mathrm{~mA} \cdot \mathrm{cm}^{-2}$ and $4.0 \mathrm{~mA} \cdot \mathrm{cm}^{-2}$ respectively, the current densities are substantially higher, thus confirming earlier trends of our previous studies [27, 39]. This behavior implies the comfortable applicability of the platinized NPG as catalyst in the FA oxidation process. The reasonable durability performance of the de-alloyed catalyst lasting for over 2500 cycles also supports this conclusion. The support of the latter statement could be extended by a comparison with tests carried out in our previous work whereby Pt coating on both, as-synthesized and de-alloyed $\mathrm{Cu}_{3} \mathrm{Au}$ nanorods were confirmed to make high activity and good durability catalysts for FA oxidation. More specifically, the peak current densities of about 3.5 to $5.5 \mathrm{~mA} . \mathrm{cm}^{-2}$ for as synthesized and de-alloyed $\mathrm{Cu}_{3} \mathrm{Au}$ nanorods, respectively are exceeded about 3 times by the Pt-NPG catalysts of the present work (10-14 mA.cm $\left.{ }^{-2}\right)$. While similar comparison was reported before for NPG-based and nanoparticulate catalysts [39], the superior durability of the NPG-based ones in comparison with their nano particulate counterparts (2500 versus 1500 cycles, respectively) has been reported for the first time in this work. Overall, Pt coated 
NPG layers fabricated by de-alloying of $\mathrm{Cu}_{\mathrm{x}} \mathrm{Au}_{(1-\mathrm{x})}$ thin films make catalysts that exhibit high activity and reasonable durability, which is comparable or better than that of nanoparticulate counterparts. Therefore, catalysts developed, characterized and tested in this work can qualify for use as a prime source of active materials for anodes in fuel cell applications.

\section{Conclusions}

Electrodeposited $\mathrm{Cu}_{\mathrm{x}} \mathrm{Au}_{(1-\mathrm{x})}$ thin films fabricated on $\mathrm{Au}$ substrates were found to exhibit unique de-alloying behaviors in comparison with their bulk counterparts and Ag-Au bulk and thin film alloys known to selectively dissolve at composition dependent critical potentials. Alternatively, the thin film alloys of interest in this work were found to de-alloy in three separate constant potential ranges. A trend was observed, not in a shift of $E_{c}$, but in the amount of de-alloyed $\mathrm{Cu}$ in each of the potential ranges for $\mathrm{Cu}_{x} \mathrm{Au}_{(1-\mathrm{x})}$ thin films with different composition. A general increase in the de-alloyed amount of $\mathrm{Cu}$ (manifested by different current magnitude in the anodic polarization curve) was seen in the most positive potential range with the decrease of the $\mathrm{Cu}$ content. Also, the use of thiosulfate in the deposition solution, known to stabilize $\mathrm{Cu}^{+}$ions, lead to collection of less charge over the course of deposition than that measured over the course of de-alloying associated with two-electron oxidation of $\mathrm{Cu}^{0}$. SA measurements by $\mathrm{Pb}$ UPD corroborated by a morphological characterization by SEM of accordingly processed NPG samples demonstrated large surface area development manifested by a roughness factor that was twice as high as that of counterparts processed by Ag-Au thin film de-alloying. The results of FA oxidation testing have shown good activity and durability performance of the NPG fabricated 
by the de-alloying $\mathrm{Cu}-\mathrm{Au}$ thin films. Both 5:1 and 1:1 ratio $\mathrm{Cu}-\mathrm{Au}$ thin film provided Pt-NPG have high current densities during FA oxidation testing, and they both survive up to 2500 cycles. Overall, the NPG generated the by de-alloying of electrodeposited $\mathrm{Cu}_{\mathrm{x}} \mathrm{Au}_{(1-\mathrm{x})}$ thin films has been found as an excellent candidate for a catalyst support in fuel cell applications.

\section{Acknowledgments}

The authors acknowledge the financial support by the National Science Foundation, Division of Chemistry, CHE-1310297. 


\section{References:}

[1] J. Erlebacher, M.J. Aziz, A. Karma, N. Dimitrov, K. Sieradzki, Evolution of nanoporosity in dealloying, Nature, 410 (2001) 450-453.

[2] A. Wittstock, J. Biener, J. Erlebacher, M. Bäumer, Nanoporous Gold : From an Ancient Technology to a High-Tech Material, Royal Society of Chemistry, 2012, pp. 1-252.

[3] Y. Ding, M.W. Chen, J. Erlebacher, Metallic mesoporous nanocomposites for electrocatalysis, J Am Chem Soc, 126 (2004) 6876-6877.

[4] M.M. Ottakam Thotiyl, S.A. Freunberger, Z.Q. Peng, Y.H. Chen, Z. Liu, P.G. Bruce, A stable cathode for the aprotic Li-O-2 battery, Nat Mater, 12 (2013) 1049-1055.

[5] D.A. McCurry, M. Kamundi, M. Fayette, F. Wafula, N. Dimitrov, All Electrochemical Fabrication of a Platinized Nanoporous Au Thin-Film Catalyst, Acs Appl Mater Inter, 3 (2011) 4459-4468.

[6] J. Xia, R. Rooney, S. Ambrozik, L. Bromberg, N. Dimitrov, Enhanced Adhesion of Ultrathin Nanoporous Au Deposits by Electrochemical Oxidation of Glassy Carbon, J. Electrochem. Soc., 162 (2015) H308-H316.

[7] L. Bromberg, J. Xia, R. Rooney, N. Dimitrov, Enhanced Adhesion of Continuous Nanoporous Au Layers by Thermochemical Oxidation of Glassy Carbon, Coatings, 4 (2014) 416-432.

[8] L. Bromberg, J. Xia, M. Fayette, N. Dimitrov, Synthesis of Ultrathin and Continuous Layers of Nanoporous Au on Glassy Carbon Substrate, J. Electrochem. Soc., 161 (2014) D3001-D3010.

[9] M. Kamundi, L. Bromberg, P. Ogutu, N. Dimitrov, Seeding strategies for the deposition of high density network of nanoporous Au cluster catalyst on glassy carbon electrodes, J Appl Electrochem, 43 (2013) 879-890.

[10] J.X. Xia, S. Ambrozik, C.C. Crane, J.Y. Chen, N. Dimitrov, Impact of Structure and Composition on the Dealloying of CuxAu(1-x) Bulk and Nanoscale Alloys, J Phys Chem C, 120 (2016) 2299-2308.

[11] T. Moffat, F.-R. Fan, A. Bard, Electrochemical and Scanning Tunneling Microscopic Study of Dealloying of $\mathrm{Cu}_{3} \mathrm{Au}$, J. Electrochem. Soc., 138 (1991) 3224-3235.

[12] B.G. Ateya, J.D. Fritz, H.W. Pickering, Kinetics of Dealloying of a Copper-5 Atomic Percent Gold Alloy, J. Electrochem. Soc., 144 (1997) 2606-2613.

[13] K. Sieradzki, N. Dimitrov, D. Movrin, C. McCall, N. Vasiljevic, J. Erlebacherb, The Dealloying Critical Potential, J. Electrochem. Soc., 149 (2002) B370-B377.

[14] R.Z. Yang, P. Strasser, M.F. Toney, Dealloying of $\mathrm{Cu}_{3} \mathrm{Pt}$ (111) Studied by Surface X-ray Scattering, J. Phys. Chem. C, 115 (2011) 9074-9080.

[15] S. Chen, S. Jenkins, J. Tao, Y. Zhu, J. Chen, Anisotropic Seeded Growth of Cu-M (M = Au, 
Pt, or Pd) Bimetallic Nanorods with Tunable Optical and Catalytic Properties, J. Phys. Chem. C, (2013) 8924-8932.

[16] M. Kamundi, L. Bromberg, E. Fey, C. Mitchell, M. Fayette, N. Dimitrov, Impact of Structure and Composition on the Dealloying of $\operatorname{AuxAg}(1-x)$ Alloys on the Nanoscale, J. Phys. Chem. C, 116 (2012) 14123-14133.

[17] S.V. Jenkins, S. Chen, J. Chen, Gold-Copper Alloyed Nanorods for Metal-catalyzed Organic Reactions: Implication of Surface Ligands on Nanoparticle-based Heterogeneous Catalysis, Tetrahedron Lett., 56 (2015) 3368-3372.

[18] D. Kim, J. Resasco, Y. Yu, A.M. Asiri, P. Yang, Synergistic geometric and electronic effects for electrochemical reduction of carbon dioxide using gold-copper bimetallic nanoparticles, Nature Communications, 5 (2014) 1-8.

[19] C.M. Andolina, A.C. Dewar, A.M. Smith, L.E. Marbella, M.J. Hartmann, J.E. Millstone, Photoluminescent Gold-Copper Nanoparticle Alloys with Composition-Tunable Near-Infrared Emission, J. Am. Chem. Soc., 135 (2013) 5266-5269.

[20] N.E. Motl, E. Ewusi-Annan, I.T. Sines, L. Jensen, R.E. Schaak, Au-Cu Alloy Nanoparticles with Tunable Compositions and Plasmonic Properties: Experimental Determination of Composition and Correlation with Theory, J. Phys. Chem. C, 114 (2010) 19263-19269.

[21] A. Tynkova, G.L. Katona, G.A. Langer, S.I. Sidorenko, S.M. Voloshko, D.L. Beke, Formation of $\mathrm{Cu}_{x} \mathrm{Au}_{1-\mathrm{x}}$ phases by cold homogenization of $\mathrm{Au} / \mathrm{Cu}$ nanocrystalline thin films, Beilstein J. Nanotechnol., 5 (2014) 1491-1500.

[22] R. Morrish, K. Dorame, A.J. Muscat, Formation of nanoporous Au by dealloying AuCu thin films in $\mathrm{HNO}_{3}$, Scripta Materialia, 64 (2011) 856-859.

[23] A.A. El Mel, F. Boukli-Hacene, L. Molina-Luna, N. Bouts, A. Chauvin, D. Thiry, E. Gautron, E. Gautier, T. P-Y, Unusual Dealloying Effect in Gold/Copper Alloy Thin Films: The Role of Defects and Column Boundaries in the Formation of Nanoporous Gold, ACS Applied Materials \& Interfaces, 7 (2015) 2310-2321.

[24] Y. Liu, S. Bliznakov, N. Dimitrov, Comprehensive Study of the Application of a Pb Underpotential Deposition-Assisted Method for Surface Area Measurement of Metallic Nanoporous Materials, J Phys Chem C, 113 (2009) 12362-12372.

[25] E. Herrero, J. Clavilier, J.M. Feliu, A. Aldaz, Influence of the geometry of the hanging meniscus contact on the hydrogen oxidation reaction on a $\mathrm{Pt}(111)$ electrode in sulphuric acid, J. Electroanal. Chem., 410 (1996) 125.

[26] M. Fayette, Y. Liu, D. Bertrand, J. Nutariya, N. Vasiljevic, N. Dimitrov, From Au to Pt via Surface Limited Redox Replacement of Pb UPD in One-Cell Configuration, Langmuir, 27 (2011) 5650-5658.

[27] D. Xu, S. Bliznakov, Z.P. Liu, J.Y. Fang, N. Dimitrov, Composition-Dependent Electrocatalytic Activity of Pt-Cu Nanocube Catalysts for Formic Acid Oxidation, Angew Chem Int Edit, 49 (2010) 1282-1285. 
[28] D. Strmcnik, D. Tripkovic, D. van der Vliet, V. Stamenkovic, N.M. Markovic, Adsorption of hydrogen on $\mathrm{Pt}(111)$ and $\mathrm{Pt}(100)$ surfaces and its role in the HOR, Electrochem Commun, 10 (2008) 1602-1605.

[29] T.A. Green, S. Roy, Speciation Analysis of $\mathrm{Au}(\mathrm{I})$ Electroplating Baths Containing Sulfite and Thiosulfate, J. Electrochem. Soc., 153 (2006) C157-C163.

[30] G. Senanayake, Analysis of reaction kinetics, speciation and mechanism of gold leaching and thiosulfate oxidation by ammoniacal copper(II) solutions, Hydrometallurgy, 75 (2004) 55-75.

[31] Y. Liu, S. Bliznakov, N. Dimitrov, Factors Controlling the Less Noble Metal Retention in Nanoporous Structures Processed by Electrochemical Dealloying, J Electrochem Soc, 157 (2010) K168-K176.

[32] H. Okamoto, D.J. Chakrabarti, D.E. Laughlin, T.B. Massalski, The Au-Cu(Gold-Copper) System, Journal of Phase Equilibria, 8 (1987) 454-474.

[33] S.H. Wei, A.A. Mbaye, L.G. Ferreira, First-principles calculations of the phase diagrams of noble metals: Cu-Au, Cu-Ag, and Ag-Au, Physical Review B, 36 (1987) 4163-4185.

[34] O.S. Ivanova, F.P. Zamborini, Size-Dependent Electrochemical Oxidation of Silver Nanoparticles, J. Am. Chem. Soc., 132 (2010) 70-72.

[35] W.J. Plieth, Electrochemical properties of small clusters of metal atoms and their role in the surface enhanced Raman scattering, J. Phys. Chem. C, 86 (1982) 3166-3170.

[36] P.L. Breuer, M.I. Jeffrey, The reduction of copper(II) and the oxidation of thiosulfate and oxysulfur anions in gold leaching solutions, Hydrometallurgy, 70 (2003) 163-173.

[37] R. Vasilic, L.T. Viyannalage, N. Dimitrov, J. Electrochem. Soc., 153 (2006) C648.

[38] M. Fayette, J. Nutariya, N. Vasiljevic, N. Dimitrov, A Study of Pt Dissolution during Formic Acid Oxidation, Acs Catal, 3 (2013) 1709-1718.

[39] L. Bromberg, M. Fayette, B. Martens, Z.P. Luo, Y. Wang, D. Xu, J. Zhang, J. Fang, N. Dimitrov, Catalytic Performance Comparison of Shape-Dependent Nanocrystals and Oriented Ultrathin Films of Pt4Cu Alloy in the Formic Acid Oxidation Process, Electrocatalysis-Us, 4 (2013) 24-36. 


\section{Figure Captions}

Figure 1. De-alloying curves of $\mathrm{Cu}_{\mathrm{x}} \mathrm{Au}_{(1-\mathrm{x})}$ thin films with different compositions electrodeposited in solutions with $\mathrm{Cu}^{+}: \mathrm{Au}^{+}$ratios: red $5: 1$, blue $3: 1$, and green $1: 1$. Sweep rate is $1 \mathrm{mV} . \mathrm{s}^{-1}$.

Figure 2. $\mathrm{Pb}$ UPD CV curves for NPG thin films obtained by de-alloying of $\mathrm{Cu}_{\mathrm{x}} \mathrm{Au}_{(1-\mathrm{x})}$ alloys electrodeposited from solutions with $\mathrm{Cu}^{+}: \mathrm{Au}^{+}$ratios: A 1:1, B 3:1, and C 5:1. Sweep rate is $20 \mathrm{mV} \cdot \mathrm{s}^{-1}$.

Figure 3. SEM images of NPG films obtained by de-alloying of $\mathrm{Cu}_{\mathrm{x}} \mathrm{Au}_{(1-\mathrm{x})}$ alloys electrodeposited from solutions with $\mathrm{Cu}^{+}: \mathrm{Au}^{+}$ratios: A 1:1, B 5:1, and $\mathrm{C}$ de-alloyed $\mathrm{Ag}_{0.75} \mathrm{Au}_{0.25}$ for comparison. Insets: Lower resolution images showing larger portion of films' surface.

Figure 4. Potential transients depicting the Pt coating carried out by five SLRR cycles of a Pb UPD layer. Substrates used: NPG films obtained by de-alloying of $\mathrm{Cu}_{\mathrm{x}} \mathrm{Au}_{(1-\mathrm{x})}$ alloys electrodeposited from solutions $\mathrm{Cu}^{+}: \mathrm{Au}^{+}$ratio as follows: $\mathrm{A} 1: 1$ and $\mathrm{B}$ 5:1.

Figure 5. H UPD CV curves showing the surface area of Pt-NPG samples. Substrates used: NPG films obtained by de-alloying of $\mathrm{Cu}_{\mathrm{x}} \mathrm{Au}_{(1-\mathrm{x})}$ alloys electrodeposited from solutions with $\mathrm{Cu}^{+}: \mathrm{Au}^{+}$ratios: $\mathrm{A} 1: 1$ and B 5:1. The sweep rate is $50 \mathrm{mV} . \mathrm{s}^{-1}$.

Figure 6. FA oxidation CV curves showing the activity and durability of Pt-NPG samples. Substrates used: NPG films obtained by de-alloying of $\mathrm{Cu}_{\mathrm{x}} \mathrm{Au}_{(1-\mathrm{x})}$ alloys electrodeposited from solutions with $\mathrm{Cu}^{+}: \mathrm{Au}^{+}$ ratios: A 1:1 and $\mathrm{B}$ 5:1. The sweep rate is $50 \mathrm{mV} . \mathrm{s}^{-1}$.

Figure TOC. $\mathrm{Cu}-\mathrm{Au}$ thin film de-alloying curves of $\mathrm{Cu}-\mathrm{Au}$ alloys with three different compositions. Inset Images: SEM micrographs of 5:1 (red) and 1:1 (green) alloys.

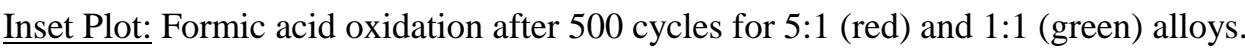




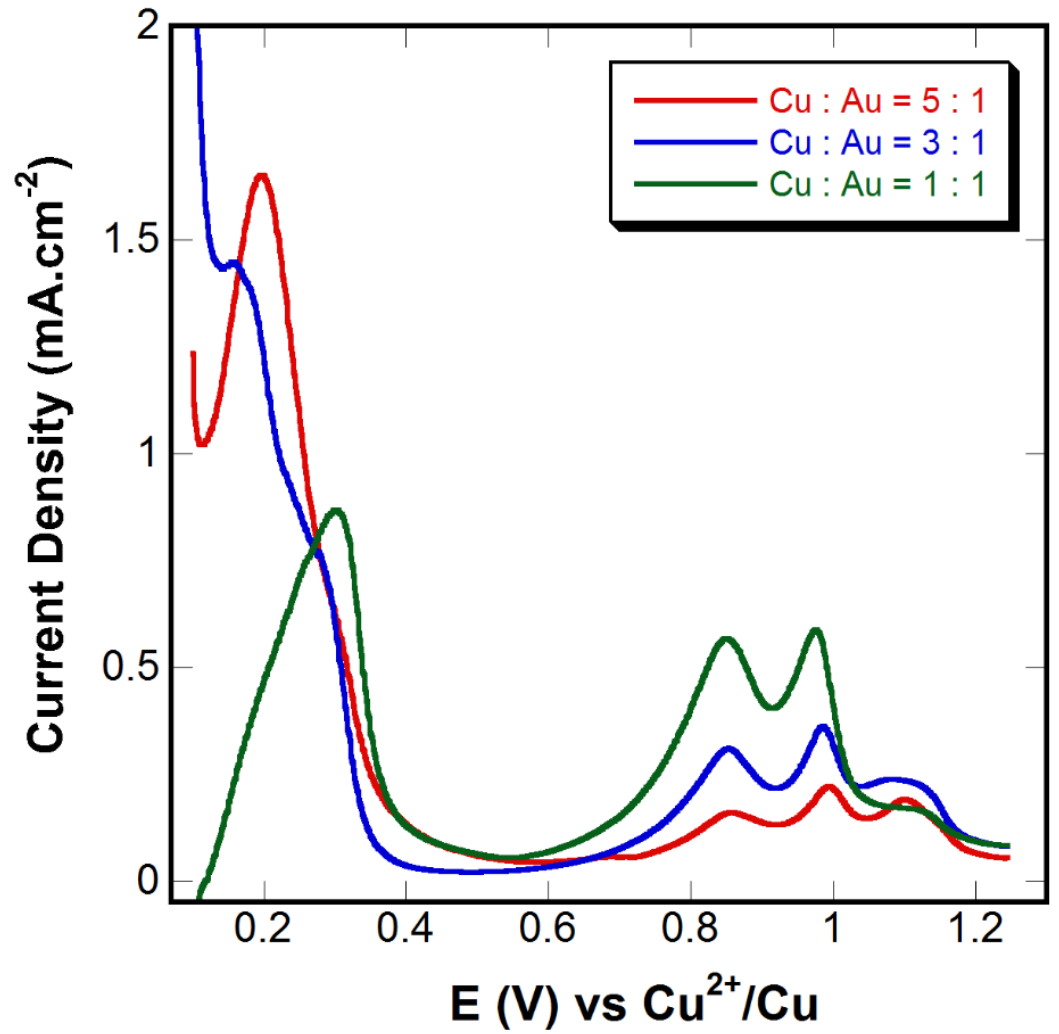



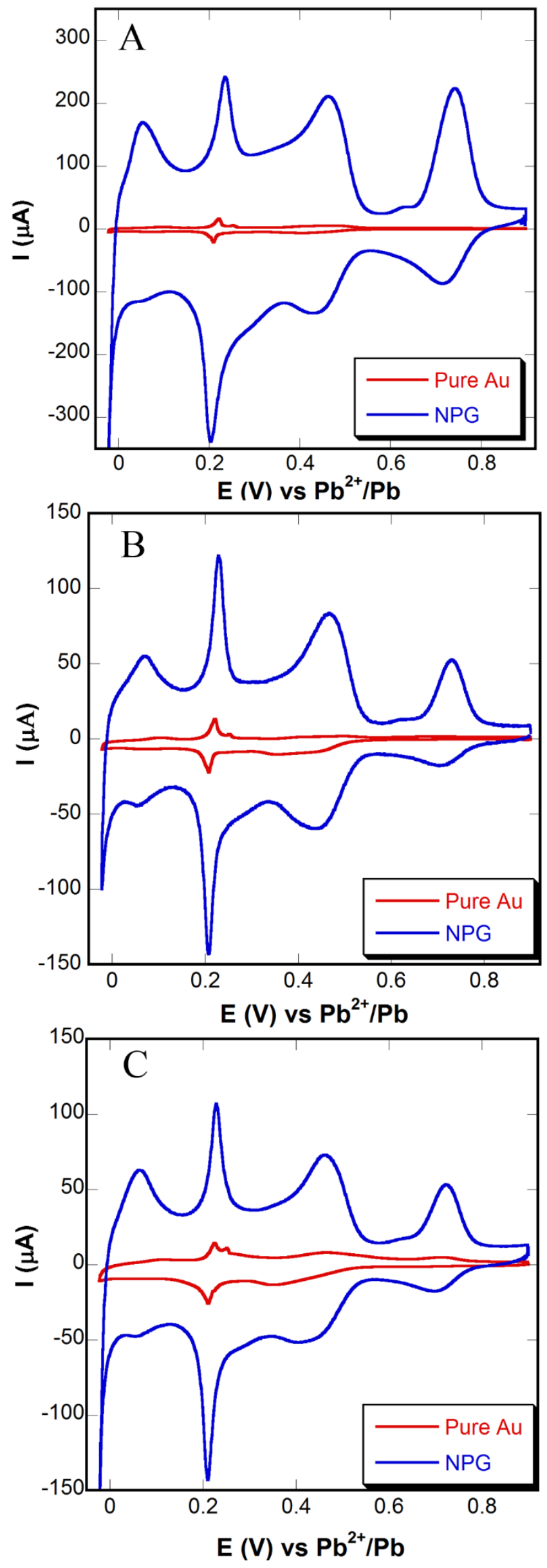

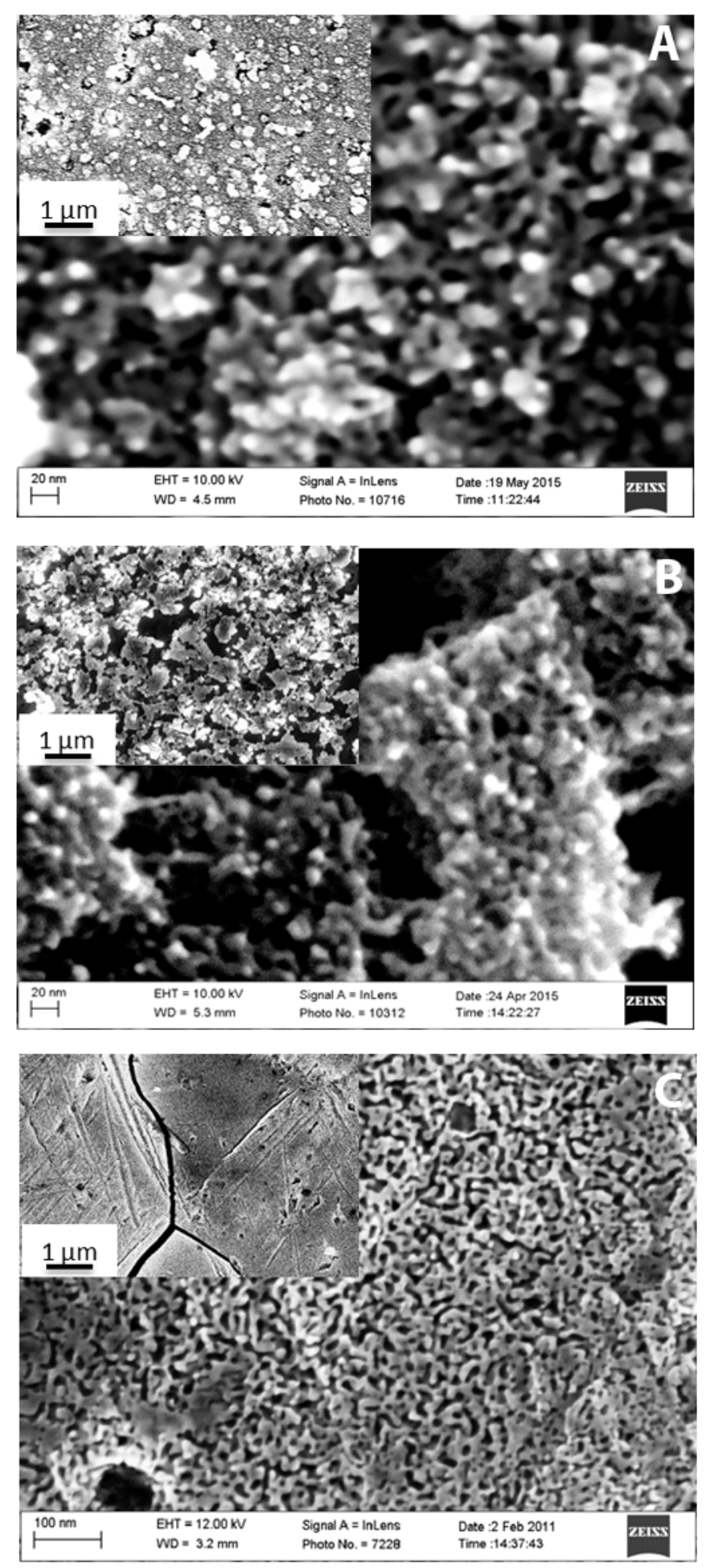

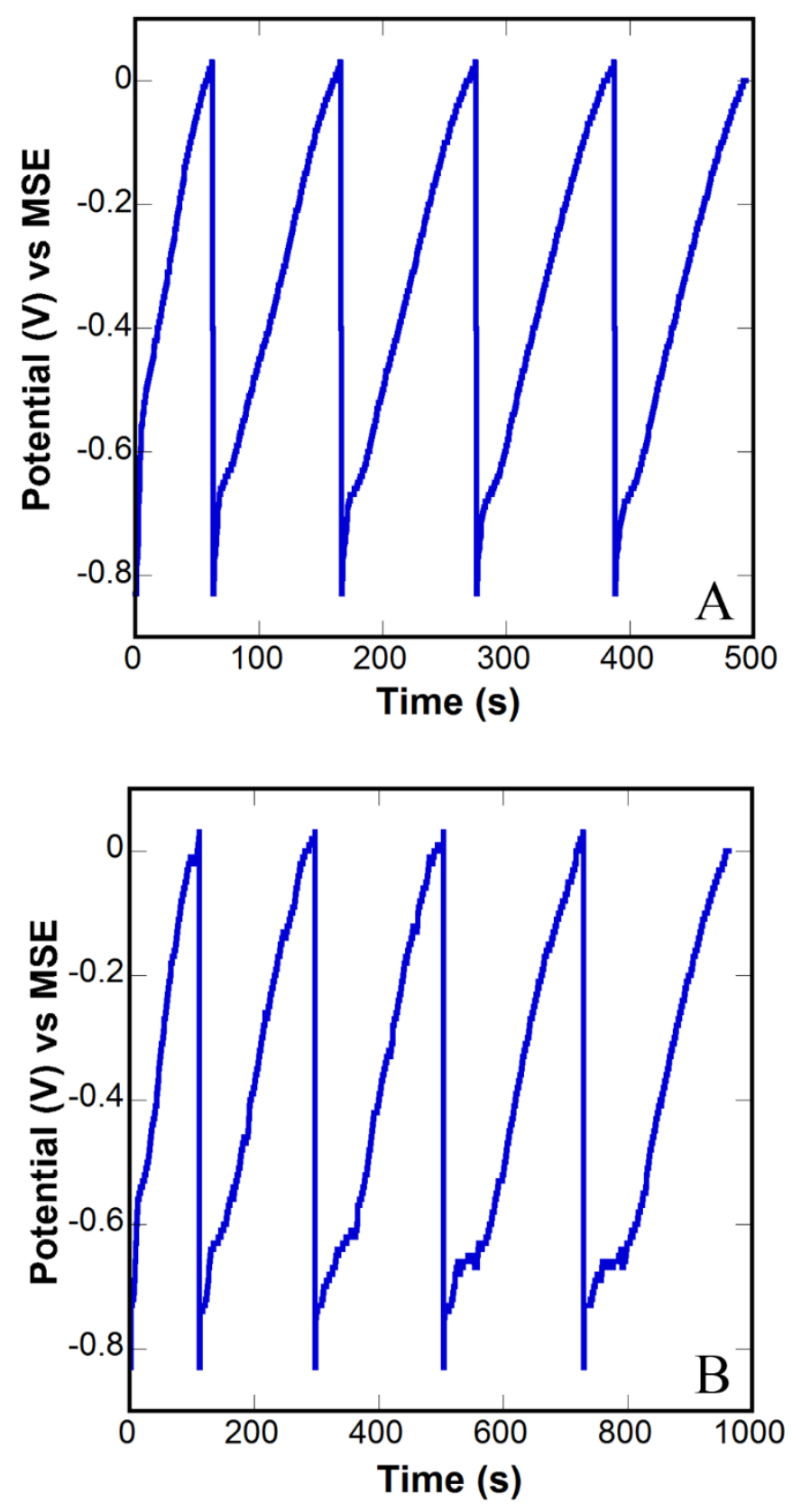

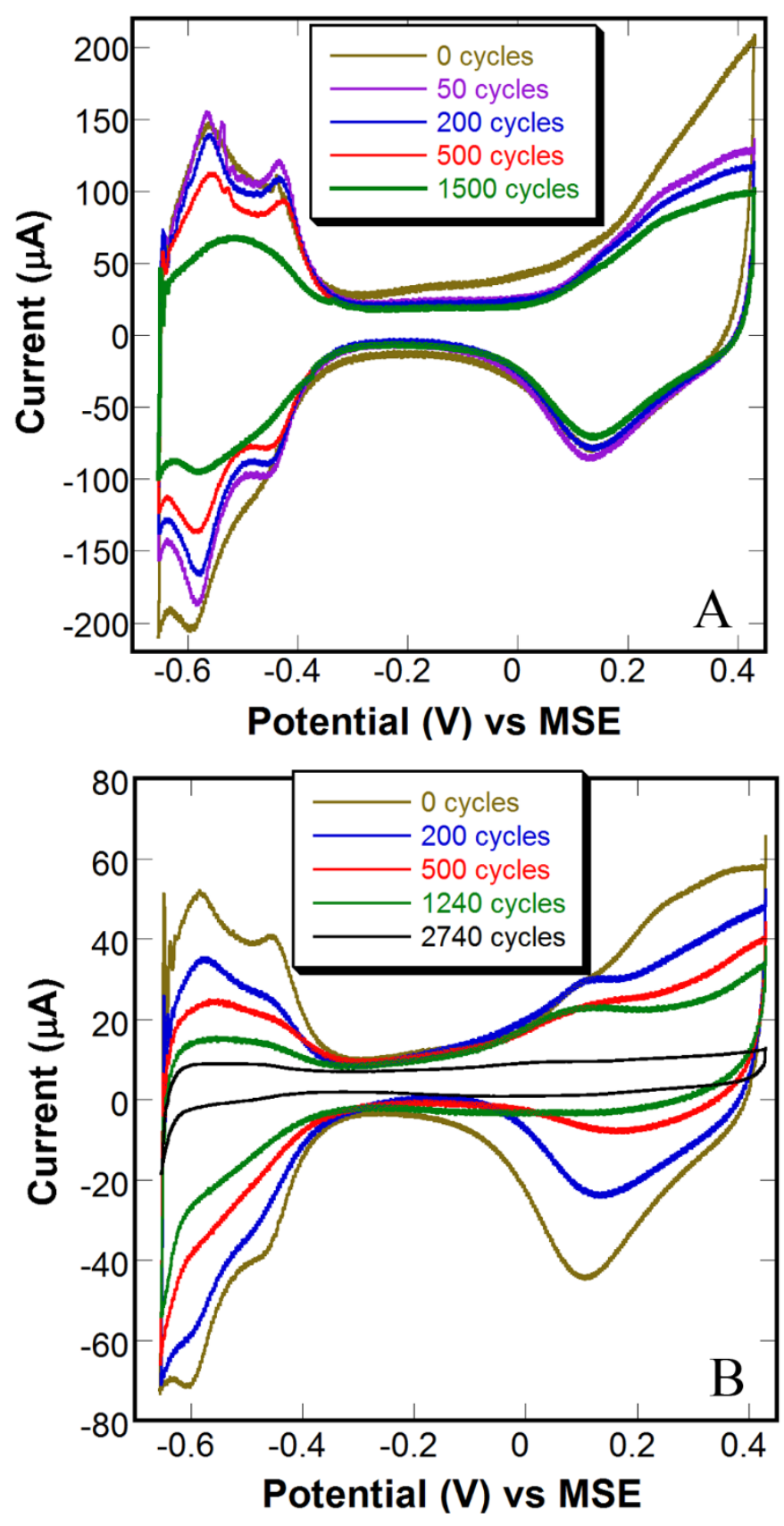

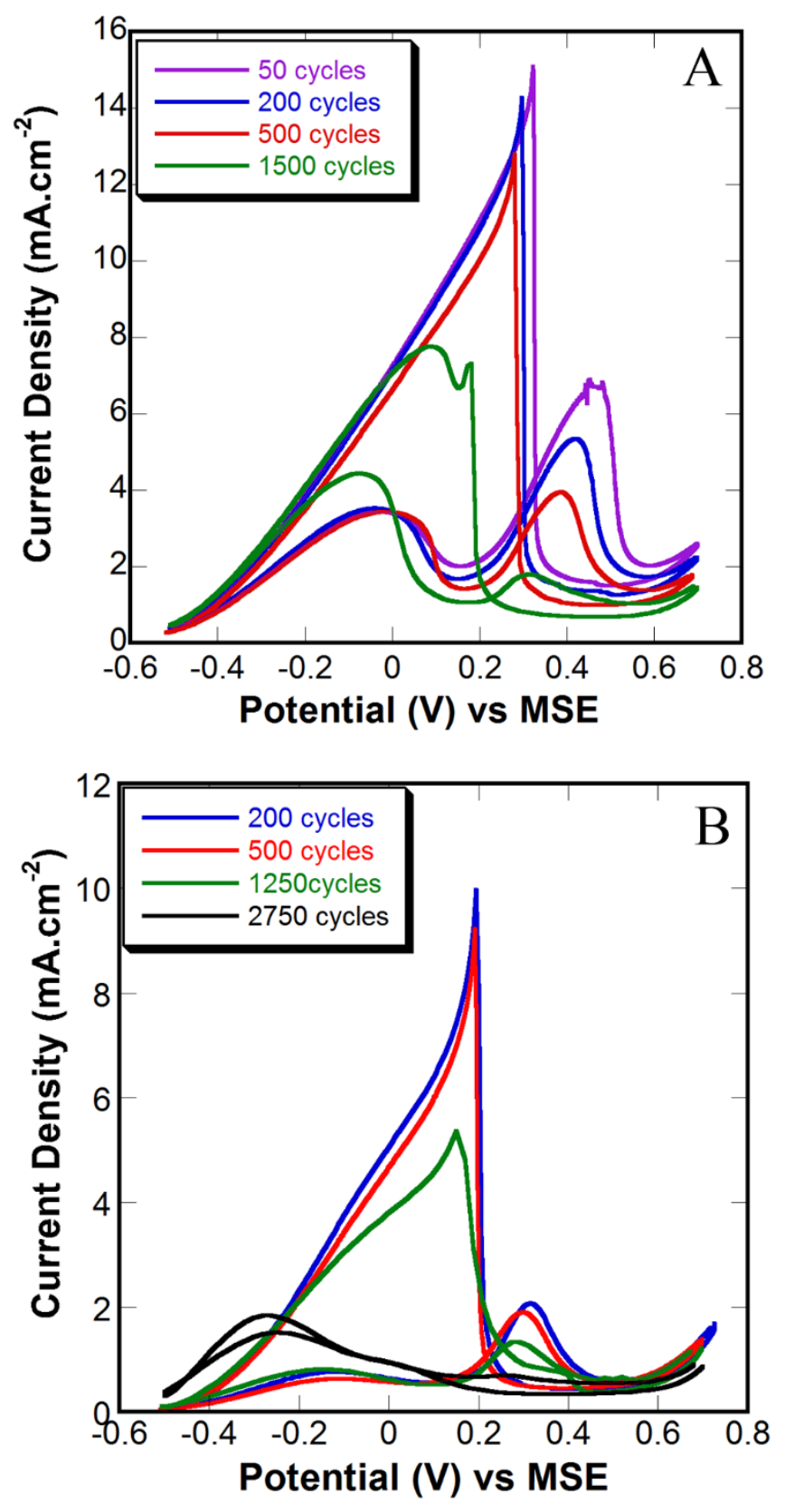
Table 1. Deposition and de-alloying charge comparison of $C u_{x} A u_{(1-x)}$ alloys with different composition.

\begin{tabular}{|c|c|c|c|c|c|c|}
\hline $\begin{array}{c}\text { Cu : Au ratio } \\
\text { deposition } \\
\text { solution; } \\
(\mathbf{E D X}, \text { in at\%) }\end{array}$ & $\begin{array}{c}\text { (A) Total } \\
\text { Charge } \\
\text { deposition } \\
\left(\mathbf{m C . c m}^{-2}\right)\end{array}$ & $\begin{array}{c}\text { (B) Stripping } \\
\text { Charge in the } \\
\text { range 0-0.4 } \mathbf{~} \\
\left(\mathbf{m C . c m}^{-2}\right)\end{array}$ & $\begin{array}{c}\text { (C) Stripping } \\
\text { Charge in } \\
\mathbf{0 . 6 - 1 . 2} \mathbf{~} \text { range } \\
\left(\mathbf{m C . c m}^{-2}\right)\end{array}$ & $\begin{array}{c}\text { (D) Stripping } \\
\text { Charge } \\
\text { ratio, } \\
(\mathbf{A}):(\mathbf{B})\end{array}$ & $\begin{array}{c}\text { (E) Total } \\
\text { Stripping } \\
\text { Charge } \\
\left(\mathbf{m C . c m}^{-2}\right)\end{array}$ & $\begin{array}{c}\text { (F) Charge Ratio } \\
(\mathbf{0 . 5} \times \mathbf{E}):(\mathbf{A})\end{array}$ \\
\hline $5: 1 \quad(82: 18)$ & 306.61 & 391.87 & 127.21 & 3.08 & 519.28 & 0.85 \\
\hline $3: 1 \quad(73: 26)$ & 214.73 & 209.03 & 122.10 & 1.71 & 331.13 & 0.77 \\
\hline $1: 1 \quad(52: 48)$ & 330.75 & 132.39 & 203.23 & 0.65 & 335.62 & 0.51 \\
\hline
\end{tabular}


Table 2. Surface area measurements on flat Au and NPG synthesized by de-alloying of $C u_{x} A u_{(1-x)}$ and $A g_{x} A u_{(I-x)}$ (from ref. 3) alloys with different composition .

\begin{tabular}{|c|c|c|c|c|}
\hline $\begin{array}{c}\text { Cu : Au ratio } \\
\text { solution; (EDX, at\%) }\end{array}$ & $\begin{array}{l}\text { Total vs (Deposition) } \\
\text { Charge }\left(\mathbf{m C} \mathrm{cm}^{-2}\right)\end{array}$ & $\begin{array}{l}\text { SA of flat Au } \\
\left(\mathrm{cm}^{2}\right)\end{array}$ & $\begin{array}{l}\text { SA of NPG } \\
\left(\mathrm{cm}^{2}\right)\end{array}$ & $\begin{array}{l}\text { SA } \\
\text { development }\end{array}$ \\
\hline $5: 1 \quad(82: 18)$ & $306.61(214.00)$ & 0.43 & $4.47(3.12)$ & $10.40(7.27)$ \\
\hline $3: 1 \quad(73: 26)$ & 214.73 & 0.40 & 5.19 & 12.99 \\
\hline $1: 1 \quad(52: 48)$ & $330.75(214.00)$ & 0.38 & 13.34 (8.63) & $35.10(22.71)$ \\
\hline $\begin{array}{c}\text { Ag : Au ratio } \\
\text { solution; (EDX, at\%) }\end{array}$ & 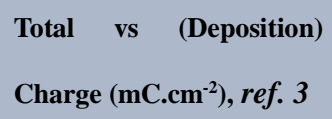 & $\begin{array}{l}\text { SA of flat Au } \\
\left(\mathrm{cm}^{2}\right), \text { ref. } 3\end{array}$ & $\begin{array}{l}\text { SA of NPG } \\
\left(\mathrm{cm}^{2}\right), \text { ref. } 3\end{array}$ & SA development \\
\hline $1: 1 \quad(70: 30)$ & 200 & 0.41 & 2.65 & 6.45 \\
\hline $3: 2 \quad(74: 26)$ & 200 & 0.38 & 2.37 & 6.24 \\
\hline $2: 1 \quad(77: 23)$ & 200 & 0.40 & 2.35 & 5.88 \\
\hline
\end{tabular}




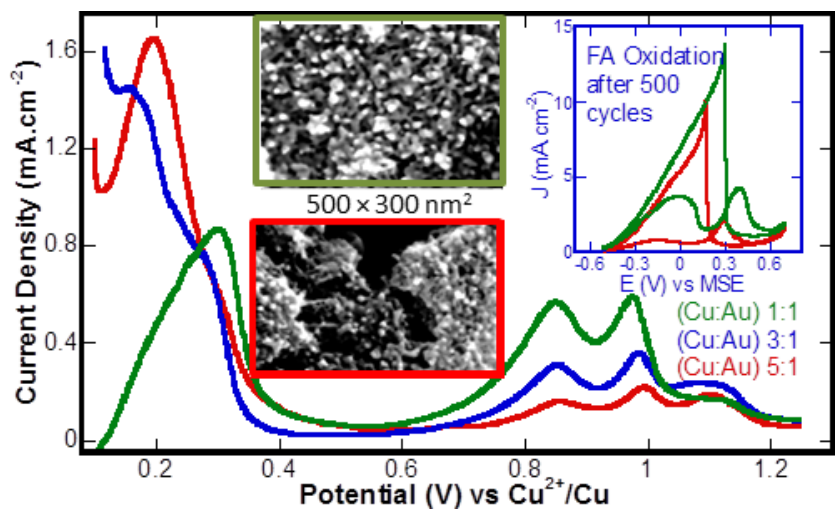

